\title{
Physalis peruviana L.: perspectiva de aplicabilidade no tratamento de câncer
}

\author{
Physalis peruviana L.: applicability perspective in cancer treatment \\ Physalis peruviana L.: perspectiva de aplicabilidad en el tratamiento del câncer
}

Recebido: 25/07/2021 | Revisado: 30/07/2021 | Aceito: 01/08/2021 | Publicado: 07/08/2021

Brenda Nayranne Gomes dos Santos ORCID: https://orcid.org/0000-0002-0561-1359 Universidade Federal do Piauí, Brasil E-mail: brendanayranne@gmail.com

Leide Maria de Soares de Sousa ORCID: https://orcid.org/0000-0002-8473-791X Universidade Federal do Piauí, Brasil E-mail: leidemaria74@hotmail.com

Nalbert Brendo Gomes dos Santos ORCID: https://orcid.org/0000-0001-5976-760X Centro Universitário Unifacid, Brasil E-mail: nalbertbrendonb@gmail.com

Aldenora Maria Ximenes Rodrigues ORCID: http://orcid.org/0000-0003-3056-0108 Universidade Federal de São Paulo, Brasil E-mail: aldenora.amxr@gmail.com

Antonia Maria das Graças Lopes Citó

ORCID: https://orcid.org/0000-0003-2605-4317 Universidade Federal do Piaú, Brasil E-mail: gracito@ufpi.edu.br

Livio Cesar Nunes Cunha

ORCID: https://orcid.org/0000-0002-1178-7940 Universidade Federal do Piauí, Brasil E-mail: liviocesar@hotmail.com

Maria Das Graças Freire De Medeiros ORCID: https://orcid.org/0000-0002-6161-7085 Universidade Federal do Piauí, Brasil E-mail: mgfmedeiros@hotmail.com

\begin{abstract}
Resumo
A Physalis peruviana L. é uma planta amplamente utilizada na alimentação por proporcionar potenciais benefícios à saúde, associadas a melhorias nos processos fisiológicos, os quais estão relacionados à presença de importantes bioativos, como os fitoesteróis, polifenóis e vitaminas $\mathrm{A}$ e $\mathrm{C}$ e por ser considerado um alimento funcional natural tem sido alvo de interesse científico e comercial devido a variedade de compostos. O presente estudo buscou realizar de forma sistemática, o levantamento de evidências científicas que possibilitem a utilização desta planta no tratamento do câncer. A revisão foi composta por estudos originais, experimentais, publicados em periódicos nacionais e internacionais, que respondiam à questão norteadora: Quais são as evidências disponíveis na literatura acerca do potencial da espécie Physalis peruviana para o tratamento do câncer? Os resultados da pesquisa demostraram que a Physalis peruviana L. e seus derivados apresentou atividades citotóxicas contra vários tipos de células cancerígenas, por diferentes mecanismos e vias apoptóticas, como ativação de Caspases 9, 8 e 3, liberação de citocromo C, ativação da proteína p53 e ativação de Bax e Bcl-2, importante mecanismo de atividade anticancerígena, além da seletividade demonstrada em alguns dos estudos, possibilitando o desenvolvimento de alternativas terapêuticas mais seguras.
\end{abstract}

Palavras-chave: Physalis peruviana; Câncer; Extratos vegetais; Vitanolides.

\begin{abstract}
Physalis peruviana L. is a plant widely used in food for providing potential health benefits, associated with melhorias in physiological processes, which are related to the presence of important bioactive, such as phytosteróis, polyphenois and vitamins $\mathrm{A}$ and $\mathrm{C}$ and to be considered $\mathrm{A}$ natural functional food has been alve of scientific and commercial interest due to a variety of compost. Either this study seeks to carry out in a systematic way, or to raise scientific evidence that it is possible to use this plant not for cancer treatment. A review was compiled by original and experimental studies published in national and international journals, responding to the guiding question: What are the evidências available in literature about the potential of the Peruvian Physalis species for the treatment of cancer? The research results will show that Physalis peruviana L. in s-eus derivatives shows cytotoxic activities against various types of cancer cells, by different mechanisms and apoptotic pathways, such as activation of Caspases 9, 8 and 3, release of cytochrome $\mathrm{C}$, activation of $\mathrm{p} 53$ protein and activation of $\mathrm{Bax}$ and $\mathrm{Bcl}-2$, an important mechanism of
\end{abstract}


anticancer activity, as well as seletivity demonstrated in some two studies, enabling or developing safer therapeutic alternatives.

Keywords: Physalis piruviana; Cancer; Vegetated extracts; Whitanolides.

\begin{abstract}
Reanudar
Physalis peruviana L. es una planta muy utilizada en la alimentación porque aporta potenciales beneficios para la salud asociados a mejoras en los procesos fisiológicos, los cuales están relacionados con la presencia de importantes bioactivos, como fitoesteroles, polifenoles y vitaminas A y C, y por ser considerada un El alimento natural funcional ha sido objeto de interés científico y comercial debido a su variedad de compuestos. El presente estudio buscó realizar un relevamiento sistemático de la evidencia científica que posibilite el uso de esta planta en el tratamiento del cáncer. La revisión consistió en estudios experimentales originales, publicados en revistas nacionales e internacionales, que respondieron a la pregunta orientadora: ¿Cuál es la evidencia disponible en la literatura sobre el potencial de la especie Physalis peruviana para el tratamiento del cáncer? Los resultados de la investigación mostraron que Physalis peruviana L. en sus derivados mostró actividades citotóxicas contra varios tipos de células cancerosas, a través de diferentes mecanismos y vías apoptóticas, como la activación de las caspasas 9, 8 y 3, liberación de citocromo C, activación de la proteína p53 y activación de Bax y Bcl-2, un importante mecanismo de actividad anticancerosa, además de la selectividad mostrada en algunos de los estudios, permitiendo el desarrollo de alternativas terapéuticas más seguras.
\end{abstract}

Palabras clave: Physalis piruviana; Cáncer; Extractos vegetales; Vitanólidos.

\title{
1. Introdução
}

O câncer é caracterizado como um grupo de doenças que possuem em comum o crescimento incontrolável e disseminação de células anormais (Inca, 2021). Embora ainda não se possa relacionar a um único fator causal, mas a vários como o tabagismo, composição da ingesta da dieta, genética, ocupação, meio ambiente e agentes infecciosos (Hanna et al., 2020; Bergers \& Fendt, 2021).

Apesar dos avanços científicos e tecnológicos na terapia e controle da progressão do câncer, a saber os diferentes tipos de tratamentos, como quimioterapia, imunoterapia, radioterapia, terapia hormonal e terapia dirigida, todas têm como desafio obter resultados terapêuticos, porém sem toxicidade (Hilal-Dandan, \& Brunton, 2015). Os efeitos colaterais e deficiências danosas significativas ainda são bem presentes e limitantes na quimioterapia. (Sedrak et al., 2021; Silveira et al., 2021). Os efeitos colaterais estão relacionados à baixa seletividade dos quimioterápicos pelas células neoplásicas, onde uma alta porcentagem de células saudáveis é destruída juntamente com as células cancerosas, e isto tem impulsionado a busca de novas fontes de fármacos.

As fontes vegetais, marinhas e de microrganismos já ocupam cerca de $60 \%$ da classe dos compostos anticancerígenos (De Almeida et al., 2020; Baloyiannis et al., 2021). As terapias naturais, como o uso de produtos derivados de plantas no tratamento do câncer apresentam vantagens sobre os produtos químicos, pois derivados de plantas são mais tolerantes, maior possibilidade de sem ligarem a receptores biológicos, consequentemente maior tolerância e menor toxicidade para as células normais, o que pode reduzir os efeitos colaterais adversos (Omara et al., 2020; Martínez-Aledo; Navas-Carrillo \& OrenesPiñero, 2020).

Acredita-se que extratos de plantas medicinais, em função da complexa combinação compostos, quimiopreventivos ou quimioterápicos, possuem mais de um mecanismo de ação e isso pode beneficiar a ação terapêutica e ao mesmo tempo, proteger contra os danos em células normais. Portanto, é essencial identificar os efeitos da combinação de extratos simples ou associado de plantas medicinais (Martínez-Aledo; Navas-Carrillo \& Orenes-Piñero, 2020; Vega et al., 2020).

A Physalis peruviana L. da família Solanaceae é uma erva arbustiva distribuída principalmente na América do Sul, constituída por uma complexa mistura de componentes bioativos, considerado como alimento funcional natural, visto que sua composição está a associadas a melhorias nos processos fisiológicos de humanos. De uso popular, seus farmacógenos são aplicados em várias doenças, como câncer, hepatite e reumatismo, destacando-se na literatura pela composição química, aspecto nutricional e farmacológico. Os frutos são de sabor agradável, semelhante ao de tomate doce, rico em vitamina, 
vitamina A e vitaminas do complexo B, (Franco et al, 2006; Huang et al., 2020; Puente, 2011; Rodríguez \& Rodríguez, 2007; Vega et al., 2020; Yu et al., 2021).

Existem mais de 80 variedades de $P$. peruviana $L$, sendo uma planta herbácea, semi arbustiva, ereta e perene em zonas subtropicais, pode crescer até atingir 0,6 a 0,9 metros, em alguns casos, atingir 1,8 metros. A flor pode ser facilmente polinizada por insetos, vento e por autopolinização. O fruto é uma baga suculenta com formato ovoide e diâmetro entre 1,25 a 2,50 cm e 4 e $10 \mathrm{~g}$ (Puente et al., 2021; Zimmer et al., 2021).

O uso popular de $P$. peruviana L., para tratamento do câncer já foram catalogadas e relacionadas as atividades antioxidantes e biológicas, elucidadas em extratos de folhas, caules e frutas, as quais que inibiram o crescimento de diferentes linhagens de células cancerígenas, efeitos protetores no fígado e em outras células, além de exibir atividade anti-inflamatória (Abou Baker et al., 2020; Ramadan et al., 2020; Franco et al, 2006; Puente, 2011; Rodríguez \& Rodríguez, 2007). A citotoxicidade dos extratos P. peruviana em células cancerígenas podem ser relacionadas as alterações de organelas mitocondriais, as quais estão envolvidas no processo de vida e morte celular (Augenlicht, L.\& Heerdt, B. 2001).

A capacidade de produção de ATP é proporcional à função mitocondrial. Quando as mitocôndrias mostram disfunção, a geração de superóxido mitocondrial (MitoSOX) pode apresentar regulação positiva substancial. Por exemplo, o manoalide induz a depleção de ATP, associada à geração de MitoSOX e morte celular em células de câncer oral (Wang et al, 2019).

Alguns estudos observaram apoptose ativada por sinalização mitocondrial em diferentes vias de sinalização, que demonstra o enorme potencial desta planta em aplicações alimentares e fitoterápicas (Yu et al., 2021; Hsieh et al., 2021; Xu et al., 2021).

Com base na descrição dos extratos ativos de $P$. peruviana, esta planta foi escolhida para as investigações da presente pesquisa que teve como objetivo realizar de forma sistemática (síntese qualitativa) o levantamento de evidências em estudos experimentais (in vivo/in vitro) buscando trazer uma síntese da utilização desta planta no tratamento do câncer.

\section{Metodologia}

O estudo se trata de uma revisão sistemática com caráter exploratório, método utilizado para responder a uma pergunta específica sobre um problema. Os estudos incluídos nessas revisões têm o delineamento de pesquisa experimental e são considerados trabalhos originais, por possuírem rigor metodológico. De forma geral, a revisão de literatura sistemática possui alto nível de evidência e se constitui em um importante documento para tomada de decisão nos contextos públicos e privados (Galvão \& Ricarte, 2019)

Para orientar este estudo, elaborou-se a seguinte questão não-clínica: Quais são as evidências disponíveis na literatura acerca do potencial da espécie Physalis peruviana para o tratamento do câncer?

A questão norteadora foi elaborada de acordo com a estratégia PICo (P - paciente; I - interesse; Co - contexto. Assim, considerou-se: P - câncer; I - Physalis peruviana; Co - efeito biológico: atividade anticâncer .

\subsection{Seleção dos estudos}

A coleta de dados foi realizada por meio de busca dos artigos científicos publicados em revistas indexadas em seis bases de dados eletrônicos: Biblioteca Virtual em Saúde (BVS), Scientific Electronic Library Online (SciELO), National Library of Medicine (PubMed), Web of Science, Scopus e o Science Direct. Para o levantamento dos estudos foram utilizados os descritores: "Physalis peruviana" e "Câncer", no idioma português cadastrados nos Descritores em Ciências da Saúde (DeCS) e inglês, de acordo com o Medical Subject Headings (MeSH) "Physalis peruviana" e "Cancer", adaptados de acordo com a base de dados utilizada. Os artigos detectados pela estratégia de busca foram avaliados pela leitura dos títulos e resumos, 
caso se adequassem a temática era feita a sua leitura na íntegra. Para sistematizar a coleta foram utilizados os operadores booleano "AND" e "OR" entre os descritores.

\subsection{Critérios de inclusão}

Foram utilizados como critérios de inclusão artigos publicados completos sem restrição de idioma, a temporal, que abordassem estudo experimental in vitro e in vivo com Physalis peruviana, ou seus derivados e isolados em avaliação de atividades anticancerígena.

\subsection{Critérios de exclusão}

Foram excluídos os artigos repetidos e revisões. Com esta triagem, foi possível se ter uma melhor visão dos efeitos da $P$. peruviana e seus isolados no tratamento do câncer.

\section{Resultados e Discussão}

Ao utilizar os descritores obteve-se um total de 470 artigos sem adição de intervalo temporal, nas seis bases de dados selecionadas, após a aplicação dos critérios de inclusão e exclusão, durante a triagem, 75 artigos foram selecionados, onde foram retirados os artigos repetidos, as revisões, restando ao final com 35 artigos, sendo distribuídos da seguinte forma nas bases de dados: 3 da Scielo, 2 da PubMed, 5 da Science Direct, 12 da Scopus, 3 da Biblioteca Virtual em Saúde e 10 da Web of Science.

Todo o processo de seleção dos artigos foi expresso pelo fluxograma a seguir (Figura 1), esses 35 artigos foram avaliados e extraídos individualmente para confecção do Quadro 1. 
Figura 1: Fluxograma do processo de seleção dos artigos.

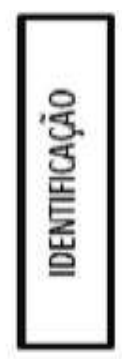

Foram inicialmente encontrados 470 artigos nas seis bases de dados

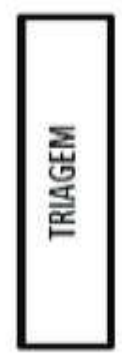

\section{Excluidos:}

\section{6 revisão}

18 livro ou capitulo de livro

212 não se enquadravam ao tema

17 teses, dissertações, relatórios

etc

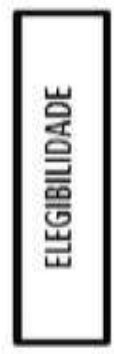

75 artigos extraidos dos bancos de dados

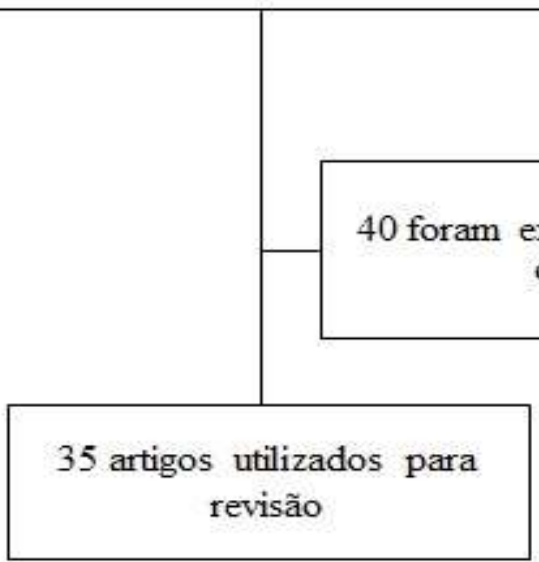

Fonte. Autores (2021). 
Research, Society and Development, v. 10, n. 10, e129101018700, 2021

(CC BY 4.0) | ISSN 2525-3409 | DOI: http://dx.doi.org/10.33448/rsd-v10i10.18700

Quadro 1: Compilado de informações extraída dos artigos selecionados.

\begin{tabular}{|c|c|c|c|c|c|}
\hline Autor & $\begin{array}{l}\text { Physalis peruviana } e \\
\text { derivados (extratos, } \\
\text { frações } e \text { isolados) }\end{array}$ & Tipo de estudo & Tipo de câncer & Posologia & Resultado observado \\
\hline Wu et el., 2004a & $\begin{array}{l}\text { Extrato etanólico de } \\
\text { folhas e toda planta }\end{array}$ & In vitro & $\begin{array}{l}\text { Fígado humano (HepG2, Hep3B e } \\
\text { PLC/PRF/5) }\end{array}$ & $10-50 \mu \mathrm{g} / \mathrm{mL}$ & $\begin{array}{l}\text { Citotoxicidade, induz apoptose e parada do ciclo } \\
\text { na fase G0/G1 e acúmulo no pico na fase sub-G1 }\end{array}$ \\
\hline Wu et Al., 2004b & $\begin{array}{l}\text { Extrato etanólico de } \\
\text { folhas e toda planta }\end{array}$ & In vitro & Fígado humano (HepG2) & $50 \mu \mathrm{g} / \mathrm{mL}$ & $\begin{array}{c}\text { Inibiu proliferação concentração dependente, } \\
\text { acúmulo no pico na fase sub-G1, induz apoptose, } \\
\text { baixa da expressão de genes anti-apoptóticos e } \\
\text { alta em pró-apoptóticos }\end{array}$ \\
\hline Zavala et al., 2006 & $\begin{array}{l}\text { Extrato etanólico das } \\
\text { folhas e caule }\end{array}$ & In vitro & $\begin{array}{l}\text { Colón humano (COLO-205) e } \\
\text { LMC humano (K562) }\end{array}$ & $\begin{array}{c}1.93 \text { e } 0.84 \\
\mu \mathrm{g} / \mathrm{mL} \text { COLO- } \\
205 \text { e } 2.42 \mathrm{e} \\
2.1 \mu \mathrm{g} / \mathrm{mL} \\
\mathrm{K} 562\end{array}$ & $\begin{array}{c}\text { Citotoxicidade com seletividade quando } \\
\text { comparado à fibroblastos }\end{array}$ \\
\hline Fouché et al., 2008 & $\begin{array}{c}\text { Extrato } \\
\text { diclorometano: } \\
\text { metanólico de folhas } \\
\text { e toda planta }\end{array}$ & In vitro & $\begin{array}{c}\text { Renal humano (TK-10), mama } \\
\text { humana (MCF-7) e melanoma } \\
\text { humano (UACC62) }\end{array}$ & $\begin{array}{c}7.25-35.59 \\
\mu \mathrm{g} / \mathrm{mL}\end{array}$ & Citotoxicidade \\
\hline Lan et al., 2009 & $\begin{array}{c}\text { Isolados } \\
\text { phyperunolide A, } \\
\text { 4HWE, WHE e } \\
\text { withanolide C }\end{array}$ & In vitro & $\begin{array}{l}\text { Fígado humano (HepG2, HepB3), } \\
\text { pulmão humano (A549) e mama } \\
\text { humana (MCF7 e MDA-MB-231) }\end{array}$ & $\begin{array}{c}1.94-4.03 \\
\mu \mathrm{g} / \mathrm{mL}, 0.10- \\
1.48 \mu \mathrm{g} / \mathrm{mL} \\
0.31-3.20 \\
\mu \mathrm{g} / \mathrm{mL} \text { e } 0.06- \\
0 ; 8 \mu \mathrm{g} / \mathrm{mL} \\
\end{array}$ & $\begin{array}{l}\text { Maior citotoxicidade para o fígado e mama que } \\
\text { para as demais }\end{array}$ \\
\hline $\begin{array}{l}\text { Quispe-Mauricio et } \\
\text { al., } 2009\end{array}$ & $\begin{array}{l}\text { Extrato etanólico de } \\
\text { caule e folhas }\end{array}$ & In vitro & $\begin{array}{c}\text { Adenocarcinoma colorretal } \\
\text { humana (HT-29), adenocarcinoma } \\
\text { de próstata humano (PC-3) e LMC } \\
\text { humano (K562) }\end{array}$ & $\begin{array}{c}5.6-249 \mu \mathrm{g} / \mathrm{mL} \\
\text { e } 6.1-206 \\
\mu \mathrm{g} / \mathrm{mL}\end{array}$ & $\begin{array}{c}\text { Citotoxicidade maior para próstata e menor para } \\
\text { leucemia }\end{array}$ \\
\hline
\end{tabular}


Research, Society and Development, v. 10, n. 10, e129101018700, 2021

(CC BY 4.0) | ISSN 2525-3409 | DOI: http://dx.doi.org/10.33448/rsd-v10i10.18700

\begin{tabular}{|c|c|c|c|c|c|}
\hline Wu et al., 2009 & $\begin{array}{l}\text { Extrato de dióxido de } \\
\text { carbono supercrítico- } \\
5\end{array}$ & In vitro & Pulmão humano (H661) & $\begin{array}{c}1,10,30,50 \mathrm{e} \\
100 \mu \mathrm{g} / \mathrm{mL}\end{array}$ & $\begin{array}{l}\text { Inibiu proliferação, induziu apoptose, acumulo no } \\
\text { pico Sub G1 e causou fragmentação do DNA, } \\
\text { aumentou a expressão de Bax e p53 e induziu } \\
\text { parada do ciclo na fase S. }\end{array}$ \\
\hline Yen et al., 2010 & Isolado 4HWE & In vitro & Pulmão humano (H1299) & $\begin{array}{l}1,5 \text { e } 10 \\
\mu \mathrm{g} / \mathrm{mL}\end{array}$ & $\begin{array}{l}\text { Dano significativo ao DNA, inibição da } \\
\text { proliferação celular com ação dose dependente, } \\
\text { parada no ciclo na fase G1 e meio da fase G2/M e } \\
\text { apoptose a } 5 \mu \mathrm{g} \text { depois de } 24 \mathrm{~h}\end{array}$ \\
\hline Chiu et al., 2013 & Isolado 4HWE & In vitro & Cavidade oral humano (Ca9-22) & $\begin{array}{c}1,2,5 \text { e } 10 \\
\mu \mathrm{g} / \mathrm{mL}\end{array}$ & $\begin{array}{c}\text { Diminuição substancial da viabilidade celular, } \\
\text { IC }_{50} \text { de } 3,6 \text { e } 1,9 \text { em } 24 \text { e } 48 \mathrm{~h} \text {, aumento de ROS e } \\
\text { da despolarização da membrana mitocondrial, } \\
\text { danos ao DNA seletivo, parada no ciclo na fase } \\
\text { G1 e meio da fase G2/M e indução de apoptose } \\
\text { seletiva. } \\
\end{array}$ \\
\hline $\begin{array}{l}\text { Areiza-Mazo; } \\
\text { Maldonado \& } \\
\text { Rojano, } 2013\end{array}$ & $\begin{array}{l}\text { Extrato aquoso do } \\
\text { cabo }\end{array}$ & In vitro & Colón humano (SW480 e SW620) & $\begin{array}{c}\text { Determinado } \\
\text { pelo MTT }\end{array}$ & $\begin{array}{l}\text { Efeito toxico e antiproliferativo, acúmulo no pico } \\
\text { sub G1 e em apoptose (SW480<SW620), } \\
\text { expressão do receptor de morte (SW480<SE620), } \\
\text { ativação da caspase-3 e diminuição de ROS }\end{array}$ \\
\hline $\begin{array}{l}\text { Al-Olayan et al., } \\
2014\end{array}$ & Suco & In vivo & Fígado & Livre na água & $\begin{array}{c}\text { Efeito hepatoprotetor: aumento das enzimas, } \\
\text { redução das áreas de colágeno pela redução do } \\
\text { estresse oxidativo }\end{array}$ \\
\hline Çakir et al., 2014 & $\begin{array}{l}\text { Extrato etanólico das } \\
\text { sementes }\end{array}$ & In vitro & $\begin{array}{l}\text { Adenocarcinoma de colo uterino } \\
\text { (HeLa) }\end{array}$ & $\begin{array}{l}\text { Variação por } \\
\text { teste }\end{array}$ & $\begin{array}{l}\text { Atividade antioxidante, prevenção do dano ao } \\
\text { DNA, citotoxicidade e aumento da expressão do } \\
\text { gene } \mathrm{Bcl}-2\end{array}$ \\
\hline You et al., 2014 & Isolado 4HWE & In vitro & Mama humano (MCF-7) & $\begin{array}{c}5,10,15,25 \mathrm{e} \\
50 \mu \mathrm{M}\end{array}$ & $\begin{array}{c}\text { Aumento de ROS, elevação de apoptose, induz } \\
\text { danos ao DNA e os sinaliza via de reparo de } \\
\text { junção não homologa. }\end{array}$ \\
\hline $\begin{array}{l}\text { El-meghawry el- } \\
\text { kenawy et al., } 2015\end{array}$ & $\begin{array}{l}\text { Extrato etanólico da } \\
\text { planta toda }\end{array}$ & In vivo & Pulmão & $150 \mathrm{mg} / \mathrm{Kg}$ & $\begin{array}{l}\text { Efeito protetivo devido à ação antiproliferativa e } \\
\text { antioxidante }\end{array}$ \\
\hline Henrich et al., 2015 & Isolado WHE & In vitro & Rim (ACHN, CAKI-1, SN12-C) & $\begin{array}{l}\text { Variação por } \\
\text { teste }\end{array}$ & $\begin{array}{l}\text { Aumento de apoptose aumento radicais livres, } \\
\text { juntamente, aumento da expressão de genes pro e } \\
\text { anti-apoptóticos }\end{array}$ \\
\hline Ramadan et al., 2015 & $\begin{array}{l}\text { Extrato hexânico e } \\
\text { etanólico das frutas }\end{array}$ & in vitro & $\begin{array}{l}\text { Mama humano (MCF-7) e colón } \\
\text { humano (Caco-2) }\end{array}$ & $0-3000 \mu \mathrm{g} / \mathrm{mL}$ & Atividade antioxidante e citotóxica \\
\hline Chang et al., 2016 & Isolado 4HWE & In vitro & Glioblastoma (U251MG) e mama & $20 \mathrm{ng} / \mathrm{mL}$ & Citotoxicidade, parada do ciclo em baixa \\
\hline
\end{tabular}


Research, Society and Development, v. 10, n. 10, e129101018700, 2021

(CC BY 4.0) | ISSN 2525-3409 | DOI: http://dx.doi.org/10.33448/rsd-v10i10.18700

\begin{tabular}{|c|c|c|c|c|c|}
\hline & & & (MDA-MB-231) & & concentração e apoptose em alta concentração \\
\hline Park et al., 2016 & Isolado 4HWE & In vitro & $\begin{array}{l}\text { Adenocarcinoma colorretal } \\
\text { humana (HT-29) }\end{array}$ & $0,0328-20 \mu \mathrm{M}$ & $\begin{array}{c}\text { Inibição do crescimento, parada do ciclo em } \\
\text { baixas concentrações na fase G0/G1, indução de } \\
\text { apoptose em altas concentrações, downregulation } \\
\text { de Hsp90 e PTGS2 e alterou a expressão de } 21 \\
\text { genes }\end{array}$ \\
\hline Peng et al., 2016 & Isolado 4HWE & $\begin{array}{l}\text { In vitro e in vivo } \\
\text { (xenoenxerto MDA- } \\
\text { MB-231) }\end{array}$ & Mama humana (MCF-7) & $\begin{array}{l}0-15 \mu \mathrm{M} ; 0,1 \mathrm{e} \\
1 \mathrm{mM} \text { in vitro } \\
\mathrm{e} 15 \mathrm{mg} / \mathrm{kg} \text { in } \\
\text { vivo }\end{array}$ & $\begin{array}{c}\text { Indução de danos ao DNA e apoptose decorrente } \\
\text { da geração de ROS, ativação de Nrf2, CAT e } \\
\text { SOD, redução }\end{array}$ \\
\hline Rao et al., 2016 & Isolado WM & In vitro & Pulmão humano (A549) & 3,6 e $12 \mu \mathrm{M}$ & $\begin{array}{c}\text { Citotóxico, parada de ciclo na fase } \mathrm{G} 2 / \mathrm{M} \text {, indução } \\
\text { de apoptose pela geração de ROS, upregulagion } \\
\text { de Bax e down regulation de Bcl-2 }\end{array}$ \\
\hline $\begin{array}{l}\text { Arbiastutie et al., } \\
2017\end{array}$ & $\begin{array}{c}\text { Extrato metalónico } \\
\text { das folhas }\end{array}$ & In vitro & $\begin{array}{l}\text { Adenocarcinoma de colo uterino } \\
\text { (HeLa) }\end{array}$ & $67,85 \mu \mathrm{g} / \mathrm{mL}$ & Citotoxicidade \\
\hline Hassan et al., 2017 & Suco & In vivo & $\begin{array}{l}\text { Fígado } \\
\end{array}$ & $1 \mathrm{~mL} / \mathrm{kg}$ & $\begin{array}{c}\text { Efeito antitumoral e melhora nos parâmetros } \\
\text { histológicos e bioquímicos }\end{array}$ \\
\hline Lee et al., 2017 & Isolado 4HWE & In vitro e in vivo & Fígado & $\begin{array}{l}2.5,5 \text { e } 10 \mu \mathrm{M} \\
\text { e } 11 ; 6 \mu \mathrm{g} / 10 \mathrm{~g}\end{array}$ & $\begin{array}{l}\text { Splicing de genes de apoptose. No animal s } \\
\text { apresentou uma diminuição do tumor. }\end{array}$ \\
\hline $\begin{array}{l}\text { Mier-giraldo et al., } \\
2017\end{array}$ & $\begin{array}{l}\text { Extrato etanólico e } \\
\text { isopropanólico dos } \\
\text { frutos }\end{array}$ & In vitro & $\begin{array}{c}\text { Adenocarcinoma de colo uterino } \\
\text { (HeLa) }\end{array}$ & $\begin{array}{c}3.13,9.5 \mathrm{e} \\
1000 \mu \mathrm{g} / \mathrm{mL}\end{array}$ & $\begin{array}{c}\text { Citotoxicidade e redução da liberação das } \\
\text { interleucinas IL-6, IL8 e MCP-1 de maneira dose } \\
\text { dependente }\end{array}$ \\
\hline Xu et al., 2017 & Isolado 17-BHWs & In vitro & Próstata humana (22Rv1 e LNCaP & $0.06-0.94 \mu \mathrm{M}$ & $\begin{array}{c}\text { Citotoxicidade } \\
\end{array}$ \\
\hline $\begin{array}{l}\text { Areiza-mazo et al., } \\
2018\end{array}$ & $\begin{array}{l}\text { Extrato etanólico de } \\
\text { frutas frescas e } \\
\text { extrato cetônico de } \\
\text { frutas desidratadas } \\
\end{array}$ & In vitro & Glioblastoma multiforme (T98G) & $50 \mu \mathrm{M}$ & $\begin{array}{l}\text { Proteção contra ROS, aumenta viabilidade e } \\
\text { protege o potencial de membrana mitocondrial }\end{array}$ \\
\hline $\begin{array}{l}\text { Herrera-Calderon et } \\
\text { al., } 2018\end{array}$ & $\begin{array}{l}\text { Extrato etanólico dos } \\
\text { frutos }\end{array}$ & In vitro & $\begin{array}{c}\text { Mama humana (MCF-7), } \\
\text { Adenocarcinoma colorretal } \\
\text { humana (HT-29), melanoma } \\
\text { humano (M-14), LMC (K-562), } \\
\text { próstata (DU-145) }\end{array}$ & $>20 \mu \mathrm{g} / \mathrm{mL}$ & Citotóxico \\
\hline
\end{tabular}


Research, Society and Development, v. 10, n. 10, e129101018700, 2021

(CC BY 4.0) | ISSN 2525-3409 | DOI: http://dx.doi.org/10.33448/rsd-v10i10.18700

\begin{tabular}{|c|c|c|c|c|c|}
\hline Mbaveng et al., 2018 & $\begin{array}{l}\text { Extrato metanólico } \\
\text { dos galhos }\end{array}$ & In vitro & $\begin{array}{l}\text { Mama humana (MDA-MB-321), } \\
\text { colón (HCT116) e glioblastoma } \\
\text { (U87MG) }\end{array}$ & $29.34 \mu \mathrm{g} / \mathrm{mL}$ & Citotoxicidade, \\
\hline Tang et al., 2018 & Isolado 4HWE & In vitro & Cavidade oral humano (Ca9-22) & $\begin{array}{l}0.9,1.8 \text { e } 3.6 \\
\mu \mathrm{g} / \mathrm{mL}\end{array}$ & $\begin{array}{c}\text { diminuiu a viabilidade celular, modificação da } \\
\text { morfologia, geração de ROS, acúmulo de proteína } \\
\text { H2AX e MRN (via DSB) e danos ao DNA }\end{array}$ \\
\hline $\begin{array}{l}\text { Ballesteros-Vivas et } \\
\quad \text { al., } 2019\end{array}$ & Extrato do cálice & In vitro & $\begin{array}{l}\text { Adenocarcinoma colorretal } \\
\text { humana (HT-29) }\end{array}$ & $\begin{array}{l}6.25,12.5,25 \\
50,100 \mu \mathrm{g} / \mathrm{mL}\end{array}$ & $\begin{array}{l}\text { Aumento da expressão de genes pró-apoptoticos, } \\
\text { alteração na expressão de genes antioxidantes, } \\
\text { anti-proliferativa }\end{array}$ \\
\hline Ye et al., 2019 & Isolado 4HWE & $\begin{array}{l}\text { In vitro e in vivo } \\
\text { (xenoenxerto } \\
\text { HCT116) }\end{array}$ & Colón humano (HCT116) & $0,09 \mu \mathrm{M}$ & $\begin{array}{l}\text { Degradação da } \beta \text {-catenina, citotóxico, parada do } \\
\text { ciclo na fase G0/G1 }\end{array}$ \\
\hline $\begin{array}{l}\text { Abou Baker \& Rady, } \\
2020 \\
\end{array}$ & $\begin{array}{l}\text { Extrato acetato de } \\
\text { etila do cálice e }\end{array}$ & In vitro & Fígado humano (HepG2) & $10-100 \mu \mathrm{g} / \mathrm{mL}$ & Citotoxicidade \\
\hline Hsieh et al., 2021 & Isolado 4HWE & In vitro & $\begin{array}{c}\text { Colón (HCT116) e pulmão } \\
\text { humano (A549) }\end{array}$ & $0.2-1 \mu \mathrm{M}$ & $\begin{array}{l}\text { Inibição de expressão de TNF- } \alpha \text {, citotoxicidade e } \\
\text { indução de apoptose. }\end{array}$ \\
\hline Yu et al., 2021 & Isolado PHA & In vitro & $\begin{array}{l}\text { Mama humana (MCF-7, MDA- } \\
\text { MB-231 e SKBR3) }\end{array}$ & $\begin{array}{l}0.5,1,2.5,5 \mathrm{e} \\
10 \mu \mathrm{M}\end{array}$ & $\begin{array}{l}\text { Citotoxicidade, geração de ROS, parada do ciclo } \\
\text { G2/M, induz dano DNA, reduz potencial de } \\
\text { membrana da mitocôndria e induz apoptose. }\end{array}$ \\
\hline Xu et al., 2021 & Isolado 4HWE & In vitro & $\begin{array}{l}\text { Leucemia promielocíticas aguda } \\
\text { (NB-4) }\end{array}$ & $0.02 \mu \mathrm{M}$ & Citotóxica \\
\hline
\end{tabular}

Legenda: 4ß-hidrooxipitanolida E (4HWE); Withanolide E (WHE); Withametelin (WM); 17 beta-hidroxivitanolidos (17-BHWs); Fisapruína A (PHA); Leucemia mieloide crônica (LMC); Fonte. Autores (2021). 
No Quadro 1 foram descritos os diferentes tipos extratos, derivados e isolados da Physalis peruviana, as concentrações e doses utilizadas e os efeitos biológicos decorrentes dos tratamentos. O período de distribuição dos artigos varia de 2004 até 2021, com maioria publicado em 2017 (n=6), em relação ao tipo de estudo foi encontrado a análise in vitro em 33 dos estudos

Areiza-Mazo; Maldonado e Rojano (2013) observaram que o fruto da Physalis peruviana teve efeito citotóxico, seletivo e redução do crescimento de adenocarcinoma e células metastáticas de cólon, com alteração do ciclo celular, evidenciado com o aumento da porcentagem de células hipodiplóides e a indução de apoptose com ativação de caspase-3 e aumento da expressão de TRAIL-DR4 / - receptores de morte celular DR5, o último envolvido na transdução sinais apoptóticos.

Apoptose é um dos processos de morte celular mais amplamente reconhecidos como mecanismo de quimioprevenção do câncer, pois permite do ponto de vista preventivo, eliminar células anormais sem afetar as células normais vivas (Nagata, S. \& Tanaka, M. 2017). As proteínas da família Bcl-2 regulam a apoptose governando a permeabilização da membrana externa mitocondrial. Os membros da família Bcl-2, Bcl-Xl e Mcl-1 de Bcl-2 são antiapoptóticos e interrompem a apoptose. Bax, Bak, Bid, Bik, Bim e Bad são pró-apoptóticos e desencadeiam a apoptose. A caspase-3 é uma proteína efetora ativada nas vias mediada por receptor (extrínseca) e intrínseca (mitocondrial). Sua ativação é seguida pela contração celular, condensação da cromatina, fragmentação de DNA cromossômico e degradação de proteínas, que acaba por causar a morte celular (Yu et al., 2003; Choi et al., 2004; Wu et al., 2004b; Wu et al., 2009; Yen et al., 2010; You et al., 2014). Foi relatado que vários fármacos moduladores de espécies reativas de oxigênio ativam as vias apoptóticas extrínsecas (Cas-8) e intrínsecas (Cas-9); ambas as vias desencadeiam apoptose através da clivagem de moléculas de sinalização a jusante, como Cas-3, no estudo de Yu et al (2021) foi demostrado que a $P$. peruviana ativa, de maneira semelhante, Cas-9, -8 e -3 em células de câncer de mama, sugerindo que o $P$. peruviana induz um estresse oxidativo genérico, que ativa caspases apoptóticas.

Foi relatado que a P. peruviana, na forma de extrato etanólico, induziu a apoptose das células HepG2 por meio da liberação de citocromo $\mathrm{c}$ da mitocôndria no citoplasma e ativação da caspase-3 (Wu et al., 2004a). O tratamento de células de pulmão H661 com extrato dióxido de carbono supercrítico de Physalis peruviana exibiu regulação positiva das proteínas p53 e Bax, liberação de citocromo $\mathrm{C}$, e a regulação negativa de $\mathrm{Bcl}-2$, além de causar a clivagem do PARP após a ativação da caspase-3.

Wu et al., 2009 mostraram que o extrato de Physalis peruviana, obtido por processo de dióxido de carbono supercrítico, ativou o mutante p53 e causou uma expressão positiva de Bax, bem como desencadeou a expressão negativa de Bcl-2 e, consequentemente, promoveu a atividade apoptótica em células H661. Foi relatado que p53 medeia a regulação positiva de Bax. A ativação de p53 poderia levar a p53 dependente e resultou na liberação de citocromo c, ativação de caspase3 e clivagem de PARP.

Além dos compostos citados em altas concentrações, o extrato etanólico de P. peruviana induziu a parada do ciclo celular, acúmulo dependente da dose do pico sub-G1 e apoptose por disfunção mitocondrial. Na pesquisa de Yen et al., 2010, o principal composto puro, $4 \beta$-hidroxivitanolida E, inibiu o crescimento da linhagem de células de câncer de pulmão H1299, evidenciado pela parada do ciclo celular na fase G2/M.

Na pesquisa de Areiza-Mazo; Maldonado e Rojano (2013) foi demostrado uma diferença na atividade da caspase-3 entre linhagens celulares de câncer de colón SW620 e SW480, e a similaridade na porcentagem de células apoptóticas e na expressão de TRAIL-DR4 / -DR5 em ambas as linhagens celulares, esse fato pode ser devido às vias de ativação de apoptose serem diferentes em cada linhagem celular, demostrando que o extrato de a P. peruviana pode atuar em diferentes vias de sinalização de apoptose. 
A 4ß-hidroxivitanolida E, identificada como marcador de $P$. peruviana, reduziu níveis de expressão da enzima próinflamatória COX -2 e os níveis de cDNA, evidenciando que a $4 \beta$-hidroxivitanolida E pode atuar nos níveis transcricionais ou pós-transcricionais afetando a estabilidade do mRNA. (Park et al., 2016).

Na pesquisa elabora por Al-Olayan et al., 2014 foi exibido o efeito protetor da Physalis peruviana L. contra a hepatotoxicidade induzida por tetracloreto de carbono em ratos sendo mediada pela supressão do estresse oxidativo, os autores atribuíram tal efeito a presença da quercetina que é considerada um forte antioxidante devido à sua capacidade de eliminar os radicais livres e ligar os íons de metais de transição. Essas propriedades da quercetina permitem que ela iniba a peroxidação lipídica e tenha propriedades anti-inflamatórias.

Além da quercetina, extrato de Physalis peruviana L também contém kaempferol 3-O-rutinosídeo ambos conhecidos por ser um potencial antioxidante devido à sua capacidade de eliminar os radicais livres e as espécies de oxigênio ativo, como o oxigênio singlete, o radical ânion superóxido e os radicais hidroxila e a presença desses compostos poderia explicar a atividade antioxidante encontrada no extrato bruto (Shebbo, S. et al, 2020).

Dentro dos 35 artigos foram encontradas dezoito formas diferentes de Physalis peruviana e derivados, destacando sete isolados, dez tipos de extratos e suco. Para uma melhor elucidação dos efeitos biológicos observados, as evidências dos estudos foram agrupadas ao tipo extrato e ensaio experimental utilizado (in vitro e in vivo).

\subsection{Atividade anticancerígena com suco da Physalis peruviana}

Dois estudos in vivo, o Al-Olayan et al. (2014) e o Hassan et al. (2017) trouxeram os efeitos observados nos fígados de camundongos, o primeiro observou um efeito hepatoprotetor ao tratar os animais com o suco de forma livre para ingestão, além de melhora nas enzimas hepáticas e redução de áreas cicatrizadas por lesão induzida, em corroboração Hassan et al. (2017) ainda observou um efeito antitumoral da Physalis peruviana na concentração de $1 \mathrm{~mL} / \mathrm{kg}$ do animal em conjunto com uma melhora na histologia e marcadores bioquímicos dos animais, os resultados deste estudo indicaram que Bax e Bcl-2 são expressos aparentemente com uma tendência crescente em tecidos de ratos.

O p53 aumentado em ratos pode ser devido a mutações de p53 resultando em replicações desreguladas de DNA danificado, incluindo instabilidade genômica que leva ao câncer (Hassan et al., 2017). Na pesquisa de Al-Olayan et al. (2014) uma hepatoproteção foi atribuída ao suco de Physalis demostrando que este, atenuava o estresse oxidativo e inibia a fibrose em ratos tratados com tetracloreto de carbono, após a suplementação de suco, o tecido hepático apresentava um padrão lobular mais ou menos normal com leve grau de necrose e infiltração linfocítica quase comparável ao controle normal.

A composição química geral do suco de fruta Physalis peruviana $L$. apresenta muitas vantagens para seu uso na medicina. Extratos vegetais de physalis apresentam atividade antioxidante, bem como anti-hepatotóxica (Al-Olayan et al., 2014), efeitos antiproliferativos (Areiza-Mazo; Maldonado \& Rojano, 2013) e atividade anti-inflamatória (Al-Olayan et al., 2014).

\subsection{Atividade anticancerígena com Extrato da Physalis peruviana}

Como descrito anteriormente, foram observados dez tipos de extratos: etanólico, diclorometano: metanólico, dióxido de carbono supercrítico, aquoso, hexânico, metanólico, cetônico, isopropanólico, acetato de etila e extrato do cálice indeterminado, que estão distribuídos dentro de 21 estudos, alguns deles utilizaram mais de um tipo de extrato (Figura 2). 
Figura 2: Distribuição dos tipos de extrato Physalis peruviana dentro dos 21 estudos.
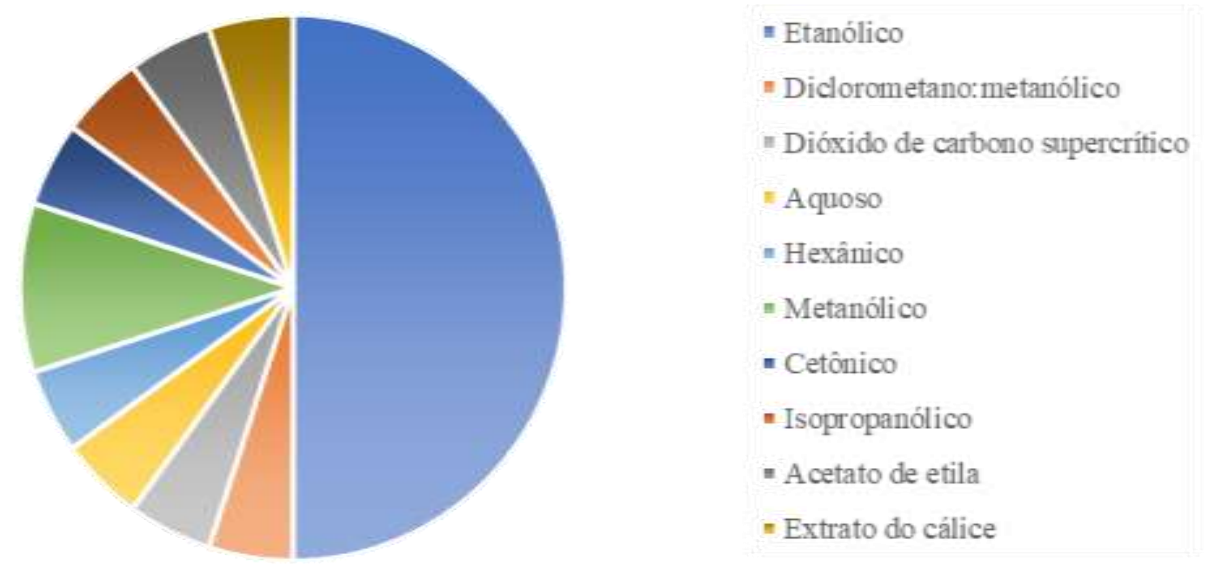

Fonte. Autores (2021).

\subsubsection{Extrato etanólico}

Iniciaremos essa parte com os estudos de $\mathrm{Wu}$ et al (2004a, b) que utilizaram dois extratos, das folhas e de toda planta contra linhagens de células hepáticas onde foram observados efeitos citotóxicos, indução de apoptose e acúmulo no pico na fase G1, além disso Wu et al (2004b) ainda observou que houve a ativação citocromo c, Smac/DIABLO, Omi/HtrA2 e da caspase 3, em conjunto com a supressão de Bcl2 e expressão de Bax.

O estudo de Mier-Giraldo et al (2017) também observou atividade citotóxica, além de redução da liberação de marcadores inflamatórios, como IL6, IL8 e MCP1 utilizando o extrato dos frutos sobre o adenocarcinoma de colo uterino, em contrapartida outro estudo usando a mesma linhagem e tratada com o extrato etanólico das sementes apresentou, apesar da citotoxicidade, ação antioxidante, aumento da expressão de Bcl2 e prevenção de danos ao DNA (Çakir et al 2014), assim como El-Meghawry El-Kenawy et al (2015) observou em um estudo in vivo em ratos com câncer de pulmão usando extrato de toda planta.

Herrera-Calderon (2018) que também usou extrato etanólico, observou a citotoxicidade em células cancerígenas de mama, colorretal, melanoma, próstata e LMC (Leucemia mieloide crônica), enquanto Zavala et al (2006) e Quispe-Mauricio et al (2009) observaram uma citotoxicidade seletiva do extrato das folhas e caule para colón e LMC no primeiro estudo e para próstata no segundo. Já Areiza-Mazo et al (2017), que também usou frutos frescos para obtenção do extrato, s, observou um aumento da viabilidade e ainda o efeito de proteger o potencial de membrana mitocondrial das células de glioblastoma.

A Figura 3 mostra a destruição dos extratos obtidos de diferentes farmacógenos de Physalis peruviana. Dez estudos utilizando cinco tipos de extratos obtidos da folha, do caule, da semente, do fruto e de toda planta para tratar nove tipos de canceres: de fígado, do colón, da LMC, da próstata, do colo uterino, do pulmão, do glioblastoma, da mama e do mieloma. 
Figura 3: Distribuição dos tipos de câncer e tipos de extratos etanólicos de Physalis peruviana presentes no estudo.

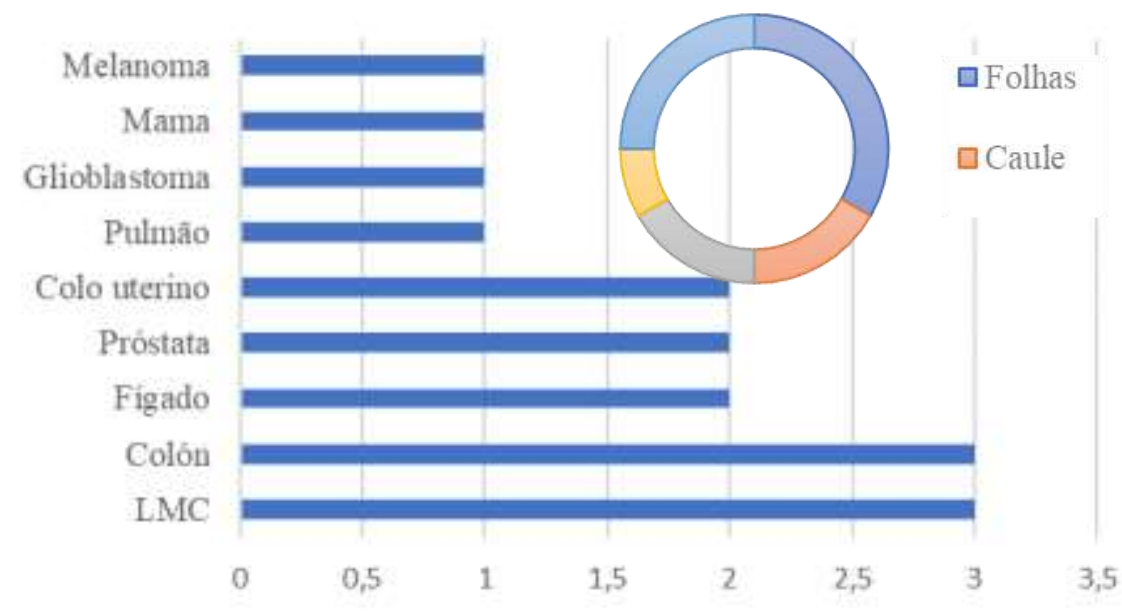

Fonte. Autores (2021).

\subsubsection{Extrato metanólico e diclorometano:metanólico}

Dos três estudos que utilizaram esses tipos de extratos, todos observaram citotoxicidade diferentes para os seis tipos de canceres e para os três farmacógenos distintos (Figura 4). Fouché et al (2008) utilizou as extrações com diclorometano:metanólico das folhas e toda planta contra linhagens celulares de mama, rim e melanoma. Arbiastutie et al (2017) avaliou os extratos das folhas contra células cancerígenas de colo uterino e Mbaveng et al (2018) utilizou os galhos nas linhas de mama, colón e glioblastoma.

O extrato orgânico de Physalis peruviana apresentou atividade potente e seletiva contra a linhagem de células cancerosas da próstata PC-3 (Fouché et al., 2008). Em contrapartida no estudo de e Mbaveng et al (2018) para adenocarcinoma de mama MDA-MB-231 ouve a ativação de caspases, depleção de MMP e aumento da produção de espécies reativas de oxigênio.

Figura 4: Distribuição dos tipos de câncer e tipos de extratos metanólicos e diclorometano:metanólico de Physalis peruviana presentes no estudo.

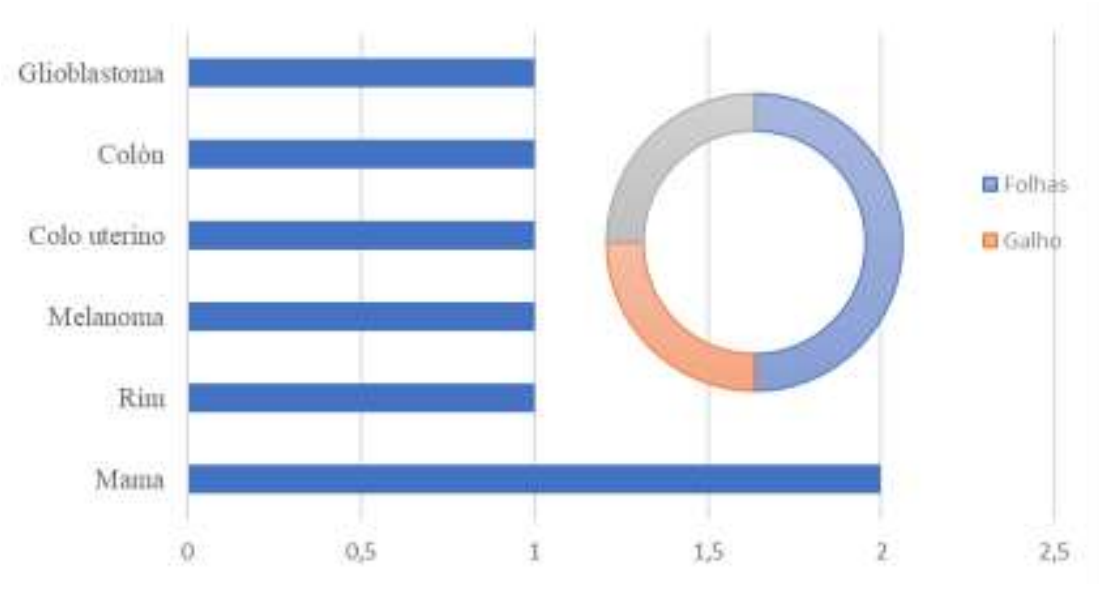

Fonte. Autores (2021). 


\subsubsection{Demais tipos de extrato}

Os outros tipos de extrato apareceram em apenas um estudo e, portanto, serão expressos em conjunto, eles são o extrato aquoso, dióxido de carbono supercrítico, hexânico, cetônico, isopropanólico, acetato de etila e extrato indeterminado do cálice.

O extrato aquoso do cabo foi utilizado frente a linhagem de colón e observou efeito antiproliferativo, com um acúmulo das células na fase G1, induziu a apoptose, a ativação da caspase 3 , assim como observado no extrato de dióxido de carbono supercrítico (Wu et al., 2009), e ação antioxidante (Areiza-Mazo; Maldonado \& Rojano, 2013). Ainda no estudo com o dióxido, Wu e colaboradores (2009) também observaram o aumento na expressão da Bax e p53, parada do ciclo na fase $\mathrm{S}$ e fragmentação do DNA nas células de pulmão.

Os extratos hexânico, cetônico e isopropanólico foram feitos a base do fruto, enquanto o primeiro e o último apresentaram efeito citotóxico contra as linhagens de colón e colo uterino, respectivamente, o segundo apresentou um efeito contrário, aumentando a viabilidade celular, além de apresentar efeito de proteção a membrana mitocondrial e ação antioxidante (Ramadan et al., 2015; Areiza-Mazo et al., 2017; Mier-Giraldo et al., 2017). Além disso o extrato hexânico ainda teve a ação antioxidante e o extrato isopropanólico reduziu alguns fatores inflamatórios (Ramadan et al., 2015; Mier-Giraldo et al., 2017).

Os dois últimos extratos são o acetato de etila e o inespecífico, em que ambos foram feitos a base do cálice da planta e apresentaram efeito citotóxico, o extrato do cálice ainda apresentou a capacidade de aumentar a expressão de genes antioxidantes e pró-apoptóticos (Ballesteros-Vivas et al., 2019; Abou Baker \& Rady, 2020).

\subsection{Atividade anticancerígena com Isolados da Physalis peruviana}

No começo da sessão foi exposto a detecção de sete tipos de isolados distintos distribuídos em 19 estudo, sendo que

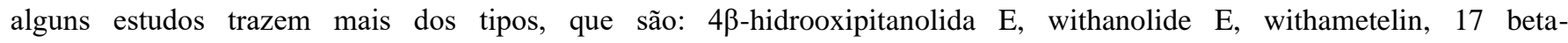
hidroxivitanolidos, fisapruína A, phyperunolide A e withanolide C (Figura 5).

Figura 5: Distribuição dos tipos de extrato de Physalis peruviana dentro dos 19 estudos.

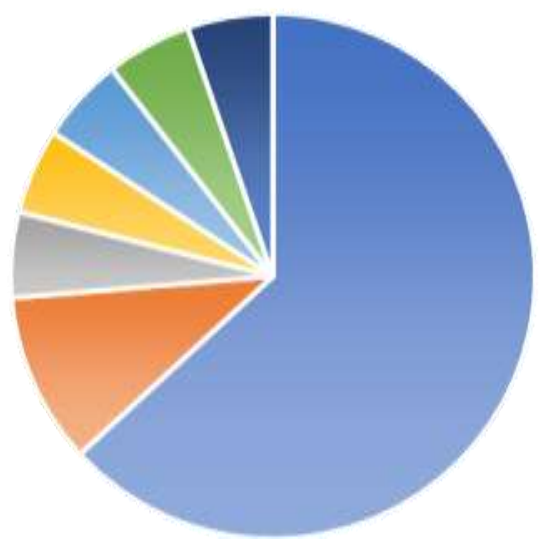

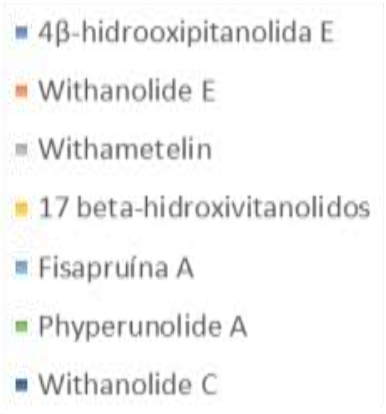

Fonte. Autores (2021).

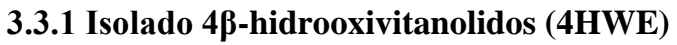

Dentro de todas as possíveis atividades que o 4HWE apresenta, sete foram as que mais se repetiram. A sua ação citotóxica foi presente em todos os estudos, exceto três (You et al., 2014; Peng et al.; 2016; Lee et al., 2017), e em uma grande variedade de linhagens: fígado, mama, pulmão, cavidade oral, glioblastoma, colón e leucemia promielocíticas aguda. 
As duas maiores atividades seguintes são a indução de apoptose, muitas vezes em altas concentrações (Chang et al., 2016; Park et al., 2016) e a parada do ciclo celular que varia na fase G0/G1, G1/G2 ou G2/M (Yen et al., 2010; Chiu et al., 2013; Park et al., 2016; Ye et al., 2019; Hseih et al., 2021). Os possíveis mecanismos associados a indução de morte do isolado foram relacionados a sua ação pró-oxidante, de causar dano ao DNA, despolarização da membrana mitocondrial e de causar alterações à expressão gênica, como aumento da expressão do gene Bax, supressão de Bcl-2, Hsp90, PTGS2 e alteração na expressão de outros 21 genes (Yen et al., 2010; Chiu et al., 2013; You et al., 2014; Chang et al., 2016; Park et al., 2016; Peng et al., 2016; Lee et al., 2017; Tang et al., 2018; Ye et al., 2019; Hseih et al., 2021).

Alguns efeitos pontuais também foram observados, como no estudo de Lee et al (2017) constatou a diminuição do tumor de fígado in vivo e o splicing dos genes HIPK3, SMAC/DIABLO e SURVIVIN, Tang et al (2018) a alterações morfológicas na célula, além do acúmulo de proteínas H2AX e MRN em células da cavidade oral e por último o estudo de Ye et al (2019) observou o aumento da degradação da $\beta$-catenina nas células de colón, o que acaba por inibia a via Wnt.

\subsubsection{Demais isolados}

O total de cinco estudos trouxeram resultados de outros seis isolados, Lan et al (2009) e Xu et al (2017) trouxeram a citotoxicidade de quatro isolados phyperunolide $\mathrm{A}$, withanolide $\mathrm{E}$, whitanolide $\mathrm{C}$ e 17 beta-hidroxivitanolidos para as linhagens de pulmão, fígado, mama e próstata, os três primeiros com ação mais intensa na linhagem de fígado e o último tendo ação na de pulmão.

Outro estudo também utilizou o isolado withanolide E contra linhagem renal, e observou um aumento de apoptose pela sensibilização de TRAIL e o aumento da expressão de genes envolvidos na apoptose (pró e anti) e uma ação pró-oxidante (Henrich et al., 2015), essa última ação é bem comum dentre os isolados e também foi observado em outros dois estudo, o de Rao et al (2016) e Yu et al (2021).

Além dessa ação o isolado withametelin (Rao et al., 2016) sobre o câncer de pulmão ainda conseguiu aumentar a expressão de Bax e redução de Bcl-2 e que essas ações conjuntas foram os responsáveis pela citotoxicidade e apoptose nas células, além disso ele também conseguiu causar parada no ciclo na fase G2/M assim como a fisapruína A no estudo de Yu et al (2021). Além desse efeito a fisapruína A também induziu dano ao DNA, produção de radicais livres e a instabilização do potencial de membrana o que acarretou citotoxicidade e apoptose nas células de mama.

\section{Conclusão}

Após todo o apanhado de dados, fica claro a forte ação da Physalis peruviana frente ao câncer, a sua ação citotóxica, pró-oxidante, de modificação da expressão genica e apoptótica que são de essenciais durante a pesquisa de novos fármacos com ação anticancerígena, em especial na tentativa de tornar cada vez mais especifica a ação do quimioterápico. Além de evidências positivas para uma grande variedade de tumores, foi demonstrado propriedade de seletividade em alguns dos estudos, potencializando a sua utilização para o desenvolvimento de produtos farmacêuticos mais seguro e eficazes para terapia oncológica.

\section{Referências}

Al-Olayan, E. M. et al (2014). The potential protective effect of Physalis peruviana L. against carbon tetrachloride-induced hepatotoxicity in rats is mediated by suppression of oxidative stress and downregulation of MMP-9 expression. Oxidative medicine and cellular longevity, 2014.

Arbiastutie, Y. et al. (2017). The potential of understorey plants from Gunung Gede Pangrango National Park (West Java, Indonesia) as cervixs anticancer agents. Biodiversitas Journal of Biological Diversity, 18 (1).

Areiza-Mazo, N. et al. (2018). Extracts of Physalis peruviana protect astrocytic cells under oxidative stress with rotenone. Frontiers in chemistry, 6, 276. 
Areiza-Mazo, N., Maldonado, M. E. \& Rojano, B. (2013). Extracto acuoso de uchuva (Physalis peruviana): actividades antiproliferativa, apoptótica y antioxidante. Perspectivas en Nutrición Humana, 15 (1), 41-55.

Augenlicht, L., Heerdt, B. (2001) Mitochondria: integrators in tumorigenesis? Nature Genetics. 28, 104-105.

Ballesteros-Vivas, D. et al. (2019). Anti-proliferative bioactivity against HT-29 colon cancer cells of a withanolides-rich extract from golden berry (Physalis peruviana L.) calyx investigated by Foodomics. Journal of Functional Foods, 63, p. 103567.

Baloyiannis, I. et al (2021). Current evidence regarding the role of adjuvant chemotherapy in rectal cancer patients with pathologic complete response after neoadjuvant chemoradiotherapy: a systematic review and meta-analysis. International Journal of Colorectal Disease, p. 1-12.

Bergers, Gabriele \& Fendt, S.M (2021). The metabolism of cancer cells during metastasis. Nature Reviews Cancer, 1-19.

Çakir, Ö. et al. (2014). Evaluation of biological activities of Physalis peruviana ethanol extracts and expression of Bcl-2 genes in HeLa cells. Food Science and Technology, 34 (2), p. 422-430.

Chang, L. C. et al. (2016) Poha berry (Physalis peruviana) with potential anti-inflammatory and cancer prevention activities. Hawai'i Journal of Medicine \& Public Health, 75, 353.

Chiu, C. C. et al. (2013). Golden berry-derived 4 $\beta$-hydroxywithanolide E for selectively killing oral cancer cells by generating ROS, DNA damage, and apoptotic pathways. PloS one, 8 (5), 64739.

De Almeida, E. M. et al. (2020) Therapeutic potential of medicinal plants indicated by the Brazilian public health system in treating the collateral effects induced by chemotherapy, radiotherapy, and chemoradiotherapy: A systematic review. Complementary therapies in medicine, $49,102293$.

El-Meghawry, El-Kenawy, A., Elshama, S. S. \& Osman, H. E. H. (2015). Effects of Physalis peruviana L on toxicity and lung cancer induction by nicotine derived nitrosamine ketone in rats. Asian Pacific Journal of Cancer Prevention, 16 (4), 5863-5868.

Fouché, G. et al. (2008). In vitro anticancer screening of South African plants. Journal of ethnopharmacology, 119 (3), $455-461$.

Galvão, M. C. B. \& Ricarte, I. L. M. (2019). Revisão Sistemática Da Literatura: conceituação, produção e publicação. Logeion: Filosofia da Informação, 6(1), $57-73$

Hanna, T. P. et al. (2020). Mortality due to cancer treatment delay: systematic review and meta-analysis. $B M J, 371$.

Hassan, H. A. et al. (2017). Cape gooseberry (Physalis peruviana) juice as a modulator agent for hepatocellular carcinoma-linked apoptosis and cell cycle arrest. Biomedicine \& Pharmacotherapy, 94, 1129-1137.

Henrich, C. J. et al. (2015). Withanolide E sensitizes renal carcinoma cells to TRAIL-induced apoptosis by increasing cFLIP degradation. Cell death \& disease, 6 (2), e1666-e1666.

Herrera-Calderon, O. et al. (2018). Phytochemical screening, total phenolic content, antioxidant, and cytotoxic activity of five peruvian plants on human tumor cell lines. Pharmacognosy Research, 10, 161.

Hilal-Dandan, R. \& Brunton, L. (2015). Quimioterapia das doenças neoplásicas. In: Manual de Farmacologia e Terapêutica de Goodman \& Gilman. Ed. 2. Editora: AMGH.

Hsieh, K.Y. et al. (2021). Golden berry $4 \beta$-hydroxywithanolide E prevents tumor necrosis factor $\alpha$-induced procoagulant activity with enhanced cytotoxicity against human lung cancer cells. Scientific reports, 11 (1), 1-12.

Huang, M. et al. (2020). Withanolides from the genus Physalis: A review on their phytochemical and pharmacological aspects. Journal of Pharmacy and Pharmacology, 72 (5), 649-669.

Lan, Y. H. et al. (2009). New cytotoxic withanolides from Physalis peruviana. Food Chemistry, 116 (2), $462-469$.

Lee, C.C. et al. (2017). 4 3 -Hydroxywithanolide E modulates alternative splicing of apoptotic genes in human hepatocellular carcinoma Huh-7 cells. Scientific reports, 7 (1), 1-13.

Martínez-Aledo, N., Navas-Carrillo, D. \& Orenes-Piñero, E. (2020). Medicinal plants: active compounds, properties and antiproliferative effects in colorectal cancer. Phytochemistry Reviews, 19 (1), 123-137.

Mbaveng, Armelle T. et al. (2018). Cytotoxicity of 18 Cameroonian medicinal plants against drug sensitive and multi-factorial drug resistant cancer cells. Journal of ethnopharmacology, 222, 21-33.

Mier-Giraldo, H. et al. (2017) Cytotoxic and immunomodulatory potential activity of Physalis peruviana fruit extracts on cervical cancer (HeLa) and fibroblast (L929) cells. Journal of evidence-based complementary \& alternative medicine, 22 (4), 777-787.

Nagata, S., Tanaka, M. (2017). Programmed cell death and the immune system. Nature Reviews Immunology, 7, 333-340.

Ohayon, S., Refua, M., Hendler, A., Aharoni, A., \& Brik, A. (2015). Harnessing the oxidation susceptibility of deubiquitinases para a inibição com pequenas moléculas. Angewandte Chemie International Edition, 54, 599-603.

Omara, T. et al. (2020) Medicinal plants used in traditional management of cancer in Uganda: a review of ethnobotanical surveys, phytochemistry, and anticancer studies. Evidence-Based Complementary and Alternative Medicine, 2020, 3529081. 
Park, E. J et al. (2016). Induction of cell cycle arrest and apoptosis with downregulation of Hsp90 client proteins and histone modification by 4ß-hydroxywithanolide E isolated from Physalis peruviana. Molecular nutrition \& food research, 60 (6), 1482-1500.

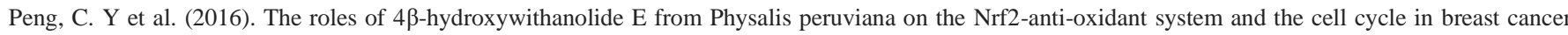
cells. The American journal of Chinese medicine, 44 (03), 617-636.

Puente, L. et al. (2021). Effects of drying methods on the characterization of fatty acids, bioactive compounds and antioxidant capacity in thin layer of physalis (Physalis peruviana L.) pulp. Journal of Food Science and Technology, 58 (4), 1470-1479.

Quispe-Mauricio, A. et al. (2009) Actividad citotóxica de Physalis peruviana (aguaymanto) en cultivos celulares de adenocarcinoma colorectal, próstata y leucemia mieloide crónica. Revista de Gastroenterología del Perú, 29 (3), 239-246.

Ramadan, Manal M. et al. (2015) Volatile compounds, antioxidants, and anticancer activities of Cape gooseberry fruit (Physalis peruviana L.): an in-vitro study. Journal of the Arab Society for Medical Research, 10 (2), 56.

Ramadan, M. F. (2020). Bioactive phytochemicals of cape gooseberry (Physalis peruviana L.). Bioactive Compounds in Underutilized Fruits and Nuts, 75-90.

Rao, P. C et al. (2016). Cytotoxicity of withasteroids: Withametelin induces cell cycle arrest at G2/M phase and mitochondria-mediated apoptosis in nonsmall cell lung cancer A549 cells. Tumor Biology, 37 (9), 12579-12587.

Rodríguez, S. \& Rodríguez, E. (2007). Efecto de la ingesta de Physalis peruviana (aguaymanto) sobre la glicemia postprandial en adultos jóvenes. Revista Médica Vallejiana, 4(1), 43-52.

Sedrak, M. S. et al. (2021). Older adult participation in cancer clinical trials: A systematic review of barriers and interventions. CA: A Cancer Journal for Clinicians, 71 (1), 78-92.

Shebbo, S., El Joumaa, M., Kawach, R \& Borjac, J. (2020) Hepatoprotective effect of Matricaria chamomilla aqueous extract against 1,2-Dimethylhydrazineinduced carcinogenic hepatic damage in mice. Heliyon. 6(6), e04082.

Shenstone, E, Lippman, Z. \& Van Eck, J. (2020). A review of nutritional properties and health benefits of Physalis species. Plant Foods for Human Nutrition, $75,316-325$.

Silveira, E. A. et al. (2021). Visceral obesity and incident cancer and cardiovascular disease: An integrative review of the epidemiological evidence. Obesity Reviews, 22 (1), e13088.

Tang, J. Y. et al. (2018). 4 -Hydroxywithanolide E selectively induces oxidative DNA damage for selective killing of oral cancer cells. Environmental toxicology, 33 (3), 295-304.

Vega, J. C et al. (2020). Conservation advances on Physalis peruviana L. and Spondia purpurea: a review. Food Science and Technology.

Wu, S. J. et al. (2004a) Antihepatoma activity of Physalis angulata and P. peruviana extracts and their effects on apoptosis in human Hep G2 cells. Life sciences, 74 (16), 2061-2073.

Wu, S. J. et al (2004b). Physalis peruviana extract induces apoptosis in human Hep G2 cells through CD95/CD95L system and the mitochondrial signaling transduction pathway. Cancer Letters. 215, 199-208.

Wu, S. J et al. (2009). Supercritical carbon dioxide extract of Physalis peruviana induced cell cycle arrest and apoptosis in human lung cancer H661 cells. Food and Chemical Toxicology, 47 (6), 1132-1138.

Xu, S.J et al. (2021) The synthesis and cytotoxic activity of derivatives of 4ß-hydroxywithanolide E. Steroids, 166, 108776.

XU, Y.M. et al. (2017). Withanolides from aeroponically grown Physalis peruviana and their selective cytotoxicity to prostate cancer and renal carcinoma cells. Journal of natural products, 80 (7), 1981-1991.

Ye, Z.N. et al. (2019). Physalis peruviana-Derived 4ß-Hydroxywithanolide E, a Novel Antagonist of Wnt Signaling, Inhibits Colorectal Cancer In Vitro and In Vivo. Molecules, 24 (6), 1146.

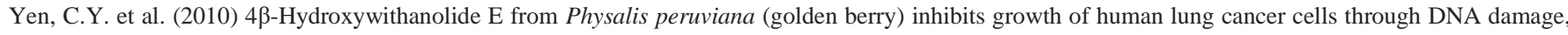
apoptosis and $\mathrm{G}$ 2/M arrest. BMC cancer, 10 (1), 1-8.

You, B.-J. et al. (2014) Non-homologous end joining pathway is the major route of protection against $4 \beta$-hydroxywithanolide E-induced DNA damage in MCF-7 cells. Food and chemical toxicology, 65, 205-212.

Yu, T. J et al. (2021). Physalis peruviana-Derived Physapruin A (PHA) Inhibits Breast Cancer Cell Proliferation and Induces Oxidative-Stress-Mediated Apoptosis and DNA Damage. Antioxidants, 10 (3), 393.

Zavala, D et al. (2006) Efecto citotóxico de Physalis peruviana (capulí) en cáncer de colon y leucemia mieloide crónica. In: Anales de la Facultad de Medicina. UNMSM. Facultad de Medicina, 283-289.

Zimmer, T. B, R. et al. (2021) Biological potential of hydroalcoholic extracts of Physalis pubescens L. Biocatalysis and Agricultural Biotechnology, 31, 101895. 